\title{
PENGEMBANGAN MEDIA AJAR BERBASIS ANDROID PADA MATERI BANGUN RUANG SISI DATAR KELAS VIII SMP
}

\author{
Ayen Arsisaria ${ }^{a}$, Fitri Apriani ${ }^{\mathbf{b}}$ \\ ${ }^{a}$ Program Studi Pendidikan Matematika STKIP Muhammadiyah Bangka Belitung \\ Jl. KH. Ahmad Dahlan, Mangkol, Pangkalanbaru, Bangka Tengah, \\ ayen.arsisari@stkipmbb.ac.id \\ ${ }^{\mathrm{b}}$ Program Studi Pendidikan Matematika STKIP Muhammadiyah Bangka Belitung \\ Jl. KH. Ahmad Dahlan, Mangkol, Pangkalanbaru, Bangka Tengah, \\ fitri.apriani@stkipmbb.ac.id
}

\begin{abstract}
Abstrak
Pada era digital ini perlunya pembaharuan dalam media ajar di kelas. Penelitian ini tentang pengembangan media pembelajaran berbasis android pada meteri bangun ruang sisi datar. Tujuan umum penelitian ini untuk mengembangkan media pembelajaran berbasis android pada materi bangun ruang sisi datar dan melihat kelayakan dari media ajar berbasis android ini. Penelitian ini merupakan penelitian pengembangan yaitu R\&D dengan model 4D. Penelitian ini dilakukan di SMPN 1 Sungai Selan di Kabupaten Bangka Tengah yang dilakukan pada tahun 2019. Subjek penelitian siswa kelas VIII SMP. Pengumpulan data dilakukan dengan menggunakan angket, wawancara. Adapun hasil penelitian ini ialah a) Pengembangan media ajar android ini melawati tahapan 4D yaitu mulai define (pendefinisian), design (perancangan), develop (pengembangan), dan disseminate (penyebaran); b) Berdasarkan penilaian oleh ahli materi diperoleh persentase 93,51\% sehingga masuk dalam kategori sangat layak, dari ahli media media ajar berbasis android mendapatkan nilai $88,04 \%$, sehingga termasuk dalam kategori sangat layak, berdasarkan penilaian oleh praktisi yaitu guru matematika SMP secara keseluruhandiperoleh persentase 97,58\% sehingga masuk dalam kategori sangat layak untuk digunakan sebagai media pembelajaran, pada hasil uji coba ke siswa diketahui bahwa seluruh pertanyaan mendapatkan "Respon Positif" dengan persentase $\geq 70 \%$ dengan rata-rata 95,3\% berada pada kategori sangat layak.
\end{abstract}

Kata Kunci: media android, bangun ruang sisi datar.

\begin{abstract}
In this digital age the need for renewal in teaching media in the classroom. This research is about developing android-based learning media on the construction of flat side space. The general objective of this research is to develop an Android-based learning media on the material to build a flat side space and see the feasibility of this Android-based teaching media. This research is a development research that is R\&D with 4D model. This research was conducted at Sungai Selan 1 Junior High School in Bangka Tengah Regency which was conducted in 2019. The research subjects were Grade VIII students of SMP. Data collection was carried out using questionnaires, interviews. As for the results of this study are a) The development of this android teaching media through 4D stages, namely starting to define, design, develop, and disseminate; b) Based on the assessment by material experts obtained a percentage of $93.51 \%$ so that it is included in the very feasible category, from experts based on android media teaching media get a value of $88.04 \%$, so that it is included in the very feasible category, based on assessment by practitioners namely junior high school mathematics teachers overall the percentage was $97.58 \%$ so that it was included in the very feasible category to be used as a learning medium, on the results of the student test it was found that all questions received a "Positive Response" with a percentage of $\geq 70 \%$ with an average of $95.3 \%$ were in the very category worthy.
\end{abstract}

Keywords: android media, build flat side space. 


\section{PENDAHULUAN}

Tantangan di era industri 4.0 saat ini adalah perkembangan IPTEK yang sangat pesat. Hal ini berimbas juga terhadap dunia pendidikan terutama dengan perkembangan perangkat smartphone yang semakin hari semakin tinggi dikarenakan harga yang rekatif murah. Peserta didik banyak memanfaatkan smartphone sebagai akses pembelajaran yang menarik dan juga semua informasi ada di dalamnya.

Menurut Suryadi (2007), sistem pembelajaran konvensional merupakan sistem yang kurang efektif untuk digunakan. IPTEK sebagai alat yang dapat membantu guru dalam pembelajaran karena siswa sekarang lebih berminat menggunakan ICT, internet, dan media sosial. Oleh karena itu, minat siswa ini harus dimanfaatkan oleh guru dalam mengajar agar tidak disalahgunakan (Puteh \& Salam, 2011).

Dikatakan oleh Fatimah \& Mufti (2014), 10\% pengguna smartphone android di Indonesia adalah anak dengan tingkatan SMP dan SMA. Menurut Muyaroah \& Fajartia (2017), penggunaan andorid sebagian besar hanya dimanfaatkan untuk media sosial saja dan sebagian kecil dimanfaatkan untuk membantu kegiatan pembelajaran. Oleh karena itu, guru agar anak tidak menyalahgunakan penggunaan android maka guru harus kreatif untuk memanfaatkannya.
Ada banyak cara yang dapat dilakukan guru dalam menciptakan proses pembelajaran yang menarik melalui smartphone android. Salah satunya adalah membuat media menggunakan smartphone android yang menunjang proses pembelajaran. Media pembelajaran memiliki peranan yang penting dalam proses belajar siswa karena bahan belajar yang bersifat abstrak bisa di kongkritkan dalam pembelajaran menggunakan animasianimasi yang disajikan (Kuswanto \& Radiansah, 2018; Novianti, 2018; Shodikin, 2017). Terutama dalam pembelajaran matematika yang dianggap abstrak oleh siswa.

Geometri merupakan salah satu bidang dalam matematika yang mempelajari titik, garis, bidang dan ruang serta sifat-sifat, ukuran-ukuran, dan keterkaitan satu dengan yang lain. Bila dibandingkan dengan bidang-bidang lain dalam matematika, geometri merupakan salah satu bidang dalam matematika yang dianggap paling sulit untuk dipahami.

Berdasarkan angket yang disebar kepada 20 siswa menyatakan bahwa guru masih jarang menggunakan media dalam pembelajaran, metode yang digunakan kebanyakan menggunakan metode ceramah, media yang digunakan menggunakan media konvensional. Tidak hanya itu di sekolah belum di dukungnya fasilitas yang memadai di ruang kelas seperti infokus, keterediaan 
wifi belum dilengkapi dengan baik. Berdasarkan gambaran di atas bahwa dalam pembelajaran matematika kebanyakan guru belum menggunakan media yang berbasis teknologi apalagi pembelajaran yang berbasis android. Padahal sebanyak $85 \%$ siswa telah menggunakan smartphone android.

Dari hasil penelitian tentang pembelajaran sub pokok bahasan geometri dengan menggunakan android antara lain Purbasari, Kahfi \& Yunus (2013) tentang Pengembangan Aplikasi Android Sebagai Media Pembelajaran Matematika pada Materi Dimensi Tiga untuk Siswa SMA Kelas $\mathrm{X}$ menyatakan bahwa media pembelajaran ini membantu siswa memahami materi dimensi tiga karena penyajian materi dilengkapi dengan gambar dan animasi; Batubara (2017) mengenai Pengembangan Media Pembelajaran Matematika berbasis Android untuk Siswa SD/MI menyatakan bahwa produk media pembelajaran berbasis android tersebut menarik minat siswa SD/MI; Pramono \& Sudarmilah (2019) tentang Game Edukasi "Petualangan Geometri" Berbasis Android menyatakan bahwa game tersebut merupakan media hiburan yang edukatif khususnya bagi siswa kelas V SD.

Pada penelitian ini, media yang akan dikembangkan adalah media pembelajaran berbasis android untuk materi bangun ruang sisi datar. Dimana sebagian siswa sekolah di
Bangka Belitung masih belum banyak menggunakan android sebagai media pembelajaran. Padahal hampir semua siswa mempunyai smartphone android. Sebenarnya banyak faktor yang dapat memepengaruhi hasil belajar salah satunya adalah pencapaian kompetensi mengajar dengan menciptakan pembelajaran yang efektif (Rahmawati \& Shendri, 2016).

Sehingga penelitian ini bertujuan mengembangkan media pembelajaran berbasis android untuk siswa SMP pada materi geometri di Kelas VIII.

\section{METODE PENELITIAN}

Jenis penelitian ini merupakan penelitian pengembangan (Research and Development / $R \& D)$. Penelitian dan pengembangan media ajar berbasis android ini dilaksanakan dengan model pengembangan 4-D (Trianto, 2012) yang meliputi 4 tahapan yaitu define (pendefinisian), design (perancangan), develop (pengembangan), dan disseminate (penyebaran).

Penelitian ini akan dilaksanakan di SMP 1 Sungai Selan Kecamatan Sungai Selan Kabupaten Bangka Tengah. Subjek dalam penelitian pengembangan ini adalah dua orang dosen ahli, satu orang guru matematika dan siswa kelas VIII SMP 1 Sungai Selan. Subjek validasi ahli adalah dosen-dosen yang sudah berpengalaman memvalidasi hasil pengembangan. 
Validasi praktisi dilakukan oleh guru mata pelajaran matematika yang ada di SMP 1 Sungai Selan. Guru juga akan menilai produk yang dikembangkan peneliti baik secara kuantitatif maupun kualitatif melalui penilaian angket. Subjek dari uji kelayakan media berbasis android adalah siswa kelas VIII SMP 1 Sungai Selan yang telah menempuh mata pelajaran Geometri.

Teknik pengumpulan data yang dilakukan dengan angket, observasi, wawancara, dan tes. Adapun instrumen yang akan digunakan dalam penelitian ini adalah: 1) Angket penilaian media oleh ahli media, ahli materi, guru; 2) angket res repons siswa; 3) Tes literasi matematika 4) lembar observasidan wawancara.

Data yang diperoleh terdiri atas data kuantitatif dan data kualitatif. Data ini merupakan data yang berkaitan dengan validasi dan tanggapan dosen ahli, guru, dan tanggapan oleh ahli bidang isi/materi dan ahli bidang desain produk yang dikembangkan dan data hasil siswa tentang media ajar berbasis android yang dikembangkan.

\section{HASIL DAN PEMBAHASAN}

A. Pengembangan Media Ajar Berbasis Android Pengembangan media ajar android ini melawati tahapan 4D yaitu mulai define (pendefinisian), design (perancangan), develop (pengembangan), dan disseminate (penyebaran).

\section{Tahap Define}

Berdasarkan hasil observasi, wawancara dan penyebaran angket di atas maka peneliti ingin mengembangkan media ajar berbasis android. Hal ini dikarenakan media pembelajaran yang memanfaatkan smartphone ini sangat mudah dan dapat digunakan secara mandiri oleh siswa. Media pembelajaran dapat digunakan kapan saja dan dimana saja karena sifatnya portable. Proses penyebarannya cukup mudah karena ukurannya tidak lebih dari 66,04 MegaByte. Proses penyebarannya dapat menggunakan kabel data, bluetooth, email, whatsApp, untuk kemudian di install secara offline. Selain penggunaan secara mandiri oleh siswa, media pembelajaran dapat digunakan oleh guru di kelas dengan bantuan laptop/PC dan LCD. Namun, untuk menggunakan media ini di PC/laptop memerlukan bantuan emulator Android dan spesifikasi laptop yang mendukung karena akan sangat berpengaruh pada kelancaran untuk mengakasesnya.

\section{Tahap Design}

Pada tahapan desain setelah dilakukan analisis awal diperoleh desain epenlitian dengan alur pada gambar di bawah ini 


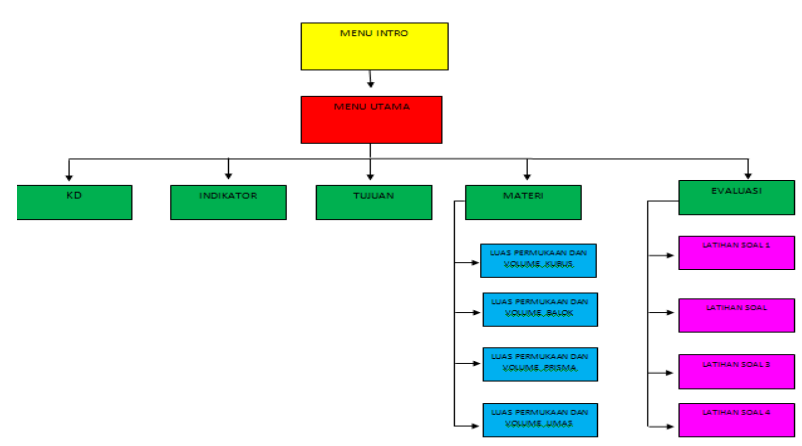

Gambar 1. Flowchart Media

\section{Development}

Pada tahapan pengembangan ini, media android yang dikembangkan menggunakan lolipop edisi 2014. Berkas paket android (Application Package File, APK) adalah format berkas yang digunakan untuk emmasang atau menditribusikan dan memasang softaware dan middleware ke ponsel dengan sistem operasi android, mirip dengan paket MSI pada windows atau Deb pada OS Debian. Dalam hal ini untuk generasi sistem android yang dapat digunakan mulai dari lolipos edisi 2014, marshmallow, nougat, hingga generasi terupdate sekarang oreo. Dalam media ini dikembangkan lolipop edisi 2014 memiliki perangkat lunak (software) dan perangkat keras (hardware). Untuk pembuatan media berbasis Android memerlukan hardware dan software yang sesuai. Software yang digunakan untuk pembuatan media ini memiliki spesifikasi sebagai berikut:
a) Power Point
b) I spring Suite
c) Web 2 APK
d) Java Script

e) Photoshop

f) Cubase 5

g) Filmora

Untuk hardware yang dibutuhkan untuk membuat media ajar ini adalah

a) Intel(R) Core(TM) i5 CPU

b) RAM 4 GB

c) Hard Disk 1 TB

Selanjutnya desain pertama membuat halaman pembuka dengan tampilan sebagai berikut:

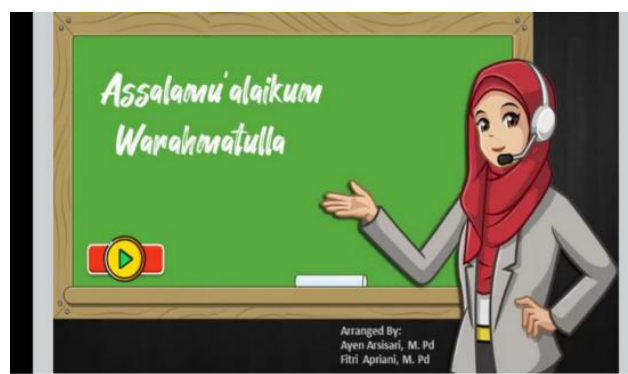

Gambar 2. Halaman Pembuka

Loading screen berdurasi 5 detik. Setelah loading screen, maka akan muncul welcome screen dengan nama aplikasi yaitu Bangun Ruang sisi datar, selanjutnya di buat halaman kedua, namun ada revisi berdasarkan validasi ahli yaitu sebagai berikut.

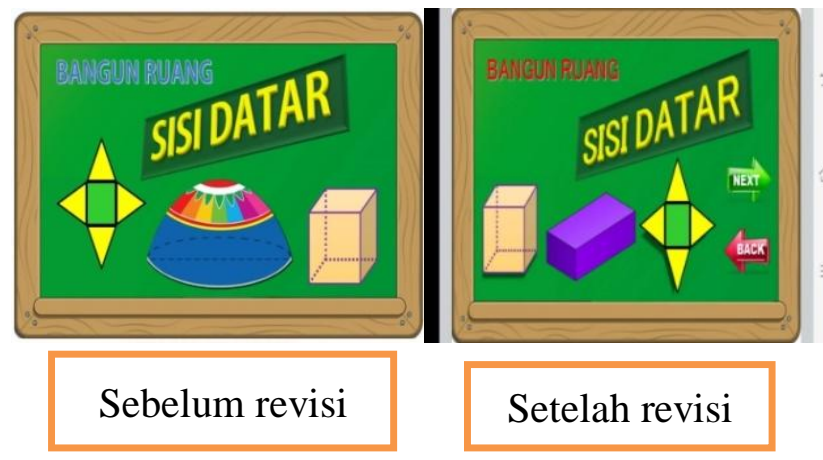

Gambar 3. Tampilan halaman ke tiga media Adanya berdasarkan hasil revisi adanya perubahan gambar tudung saji, 
karena dianggap kurang mewakili bentuk dari pada bangun runga sisi datar.

Selanjutnya pada gambar di bawah ini akan ada perbaikan pada halaman sejarah geometri mewakili bentuk dari pada bangun runga sisi datar
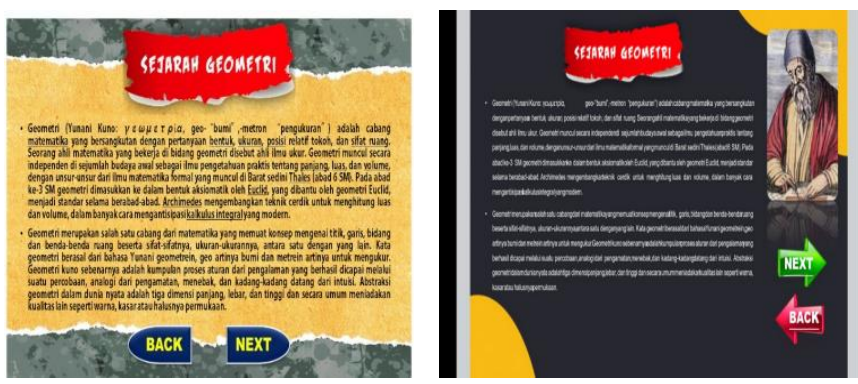

Sebelum revisi

Setelah revisi

Gambar 4. Tampilan halaman sejarah

Geometri

Halaman di buat dibuat agar siswa mengetahui sedikit dari sejarah geometri dan nama-nama ahli daripada geometri hal lain juga yang ingin di ajarkan agar siswa dapat menghargai para ilmuan yang telah berjasa menemukan konsep materi dan rumus-rumus yang luar biasa sehingga dapat membantu pekerjaan banyak manusia.

Proses revisi demi revisi terus dilakukan sehingga di peroleh tampilan sebagai berikut.

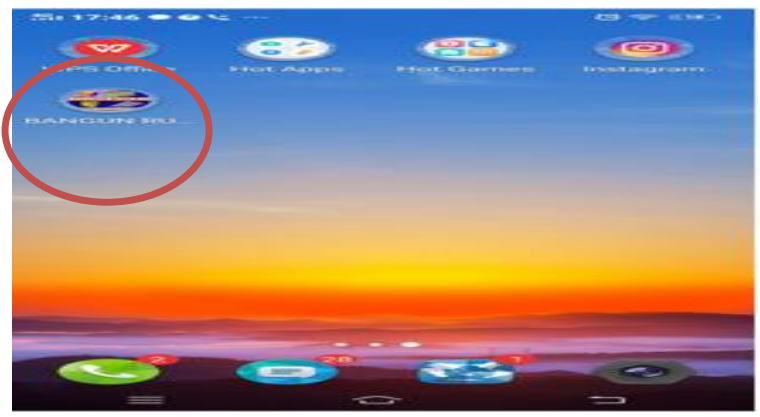

Gambar 5. Tampilan aplikasi pada smartphone pada proses pengembangan diberikan angket penilaian kepada validator yaitu ahli materi, media dan praktisi. Berikut ini salah satu hasil validasi ahli media sebagai berikut:

\section{Hasil Validasi Ahli Materi}

Ahli media memberikan ceklist bahwa media dapat digunakan namun dapat di revisi sesuai saran.

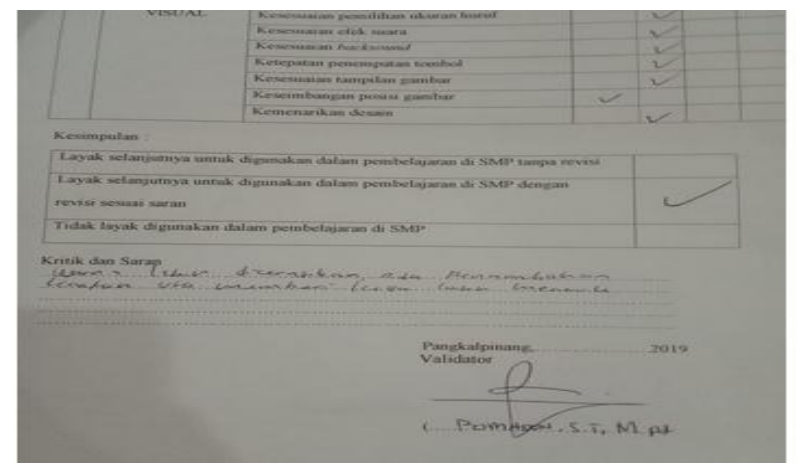

Gambar 6. Lembar Validasi Ahli Media Adapun contoh revisi yang dilakukan peneliti yaitu

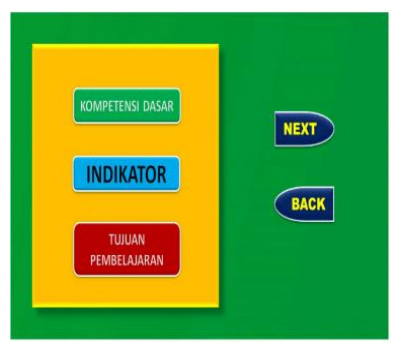

Sebelum revisi

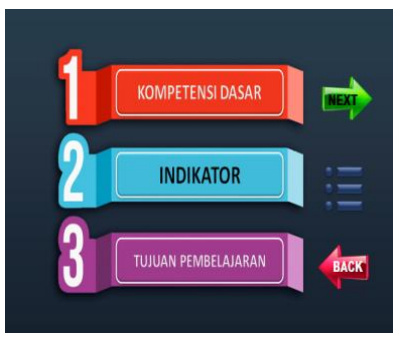

Setelah revisi
Gambar 7. Revisi Tampilan Media

Selanjutya tahapan grup terbatas dilakukan untuk mendapatkan pendapat dari siswa apakah media sesaui atau tidak dengan ranah mereka, baik dari segi tampilan dan lain-lain 


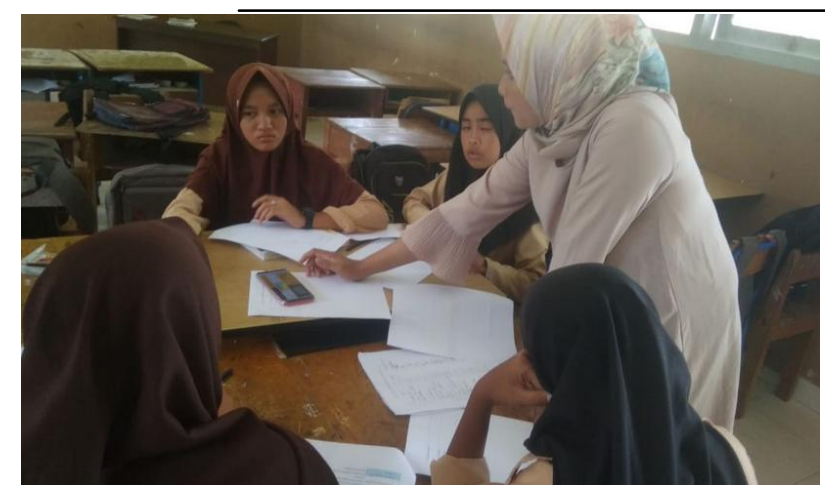

Gambar 8. Tahapan Grup Terbatas

Dari hasil small grup siswa sangat tertarik dengan media yang diberikan;

Peneliti: yoh cmana media ne, warna, gambar kek suara e jelas $\mathrm{dk}$ ?

Siswa : aok bu jelas, seru bu ok

Peneliti : pacak dak tombolnya di klik

Siswa : bisa bu

Peneliti : oh aok kan ade rumus e di situ jelas ngak?

Siswa : rumus luas permukaan prisma bu kami bingung

Peneliti : oke, apa lagi yang lainnya

Siswa $\quad$ hmm...lh bu

Peneliti : kalo media model ne ade di hp ikak ingen dak?

Siswa : aok kami mau bu.

\section{Tahap Desimination}

Tahap desiminasi dilakukan dengan menyebarkan media pembelajaran kepada siswa kelas VIII SMP 1 Sungai Selan dan Sekolah lain yaitu SMP 7 Satap Sungai Selan.

\section{B. Uji Kelayakan}

1. Validasi Media

Berdasarkan penilaian oleh ahli media secara keseluruhan, media ajar berbasis android mendapatkan nilai total 81 pada 23 indikator sehingga termasuk kategori sangat baik. Apabila dihitung dengan persentase, media ajar berbasis android mendapatkan nilai $88,04 \%$, sehingga termasuk dalam kategori sangat layak untuk digunakan sebagai media pembelajaran.

2. Validasi materi

Berdasarkan penilaian oleh ahli materi secera keseluruhan, media mendapat nilai total 101 pada 27 indikator sehingga termasuk kategori sangat baik. Apabila dihitung dengan persentase, media mendapatkan nilai $93,51 \%$ sehingga masuk dalam kategori sangat layak untuk digunakan sebagai media pembelajaran.

3. Praktisi Guru matematika

Berdasarkan penilaian oleh guru matematika SMP secera keseluruhan, media mendapat nilai total 121 pada 31 indikator sehingga termasuk kategori sangat baik. Apabila dihitung dengan persentase, media mendapatkan nilai $97,58 \%$ sehingga masuk dalam kategori sangat layak untuk digunakan sebagai media pembelajaran.

4. Siswa

Penilaian media pembelajaran juga dilakukan oleh 25 siswa di SMP N 1 Sungai Selan dengan menggunakan angket. Angket untuk siswa menggunakan skala Ghuttman dengan dua alternatif jawaban. 
Pertanyaan dalam angket terdiri dari 6 pertanyaan yang bersifat kombinasi. Berikut adalah rekapitulasi jawaban dari 25 siswa kelas VIII SMP 1 Sungai Selan.

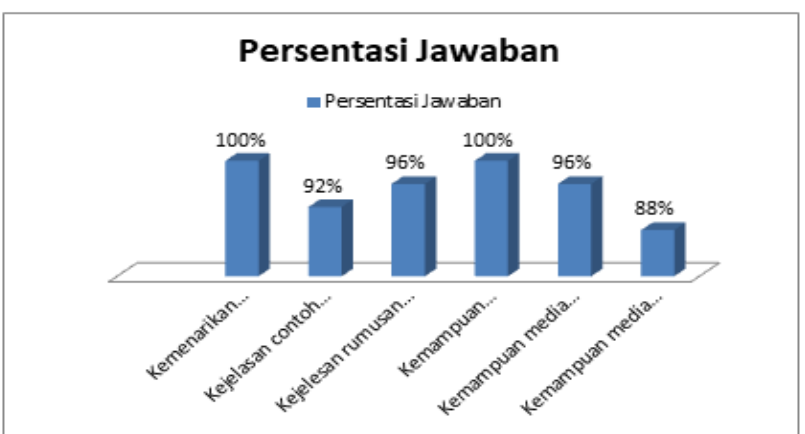

Gambar 9. Diagram Batang Persentase Jawaban Ya SiswaSetiap Indikator

Tabel 1. Rekapitulasi Pendapat Siswa Mengenai Media

\begin{tabular}{|c|l|c|c|c|c|}
\hline \multirow{2}{*}{ No } & \multicolumn{1}{|c|}{ Indikator } & \multicolumn{2}{|c|}{ Jawaban } & \multirow{2}{*}{ Jumlah } & $\begin{array}{c}\text { Persentasi } \\
\text { Jawaban }\end{array}$ \\
\cline { 4 - 5 } 1 & Kemenarikan penyampaian materi & 25 & 0 & 25 & $100 \%$ \\
\hline 2 & Kejelasan contoh soal yang diberikan & 23 & 2 & 25 & $92 \%$ \\
\hline 3 & Kejelesan rumusan soal & 24 & 1 & 25 & $96 \%$ \\
\hline 4 & Kemampuan mampu mendorong rasa & 25 & 0 & 25 & $100 \%$ \\
\hline 5 & $\begin{array}{l}\text { Kemain tahu siswa } \\
\text { meningkatkan pemahaman siswa }\end{array}$ & 24 & 1 & 25 & $96 \%$ \\
\hline 6 & $\begin{array}{l}\text { Kemampuan media dalam } \\
\text { menambah motivasi belajar siswa }\end{array}$ & 22 & 3 & 25 & $88 \%$ \\
\hline
\end{tabular}

Dari Tabel 1 di atas dapat diketahui bahwa seluruh pertanyaan mendapatkan "Respon Positif" dengan persentase $\geq$ 70\%. Berikut disajikan persentase jawaban siswa setiap pertanyaan dalam bentuk diagram batang. Berdasarkan hasil angket diperoleh 95,3\% dan pada kategori sangat layak.

\section{KESIMPULAN DAN SARAN}

Adapun kesimpulan dari hasil penelitian ini ialah
1. Pengembangan media ajar android ini melawati tahapan 4D yaitu mulai define (pendefinisian), design (perancangan), develop (pengembangan), dan disseminate (penyebaran).

2. Berdasarkan penilaian oleh ahli materi secera keseluruhan, media mendapat nilai total 101 pada 27 indikator sehingga termasuk kategori sangat baik. Apabila dihitung dengan persentase, media mendapatkan nilai 93,51\% sehingga masuk dalam kategori sangat layak untuk digunakan sebagai media pembelajaran; b) dari 
ahli media media ajar berbasis android mendapatkan nilai $88,04 \%$, sehingga termasuk dalam kategori sangat layak untuk digunakan sebagai media pembelajaran; c) Berdasarkan penilaian oleh guru matematika SMP secara keseluruhan, media mendapat nilai total 121 pada 31 indikator sehingga termasuk kategori sangat baik. Apabila dihitung dengan persentase, media mendapatkan nilai 97,58\% sehingga masuk dalam kategori sangat layak untuk digunakan sebagai media pembelajaran; d) pada hasil field test diketahui bahwa seluruh pertanyaan mendapatkan "Respon Positif' dengan persentase $\geq 70 \%$ dengan rata-rata $95,3 \%$ dari 6 item pertanyaan angket sehingga berada pada kategori sangat layak.

Adapun saran yang dapat diberikan yaitu

1. Pada era digital masa ini, ada baiknya pembelajaran sudah mengarah kepada media berbasis android

2. Baiknya tiap siswa memiliki smartphone agar pembelajaran dapat lebih lancar dalam penggunaan media berbasis android

\section{UCAPAN TERIMA KASIH}

Terima kasih diucapkan kepada pihak Kemensristekdikti yang telah memberikan kesempatan belajar dan juga memberikan dukungan dana. Kepada Dinas Pendidikan Bangka Tengah, Kepada seluruh validator, kepala sekolah serta bapak ibu guru dan siswa siswi di SMPN 1 Sungai Selan berkat kerja sama yang baik penelitian ini dapat dilaksanakan dengan lancar dan selesai sesuai waktu yang ditentukan. Semoga penelitian ini memberikan manfaat khususnya di bidang pendidikan matematika sekolah.

\section{DAFTAR PUSTAKA}

Batubara, H. H. (2018). Pengembangan Media Pembelajaran Matematika berbasis Android untuk Siswa SD/MI. Muallimuna: Jurnal Madrasah Ibtidaiyah, Vol. 3(1), pp.12-27.

Fatimah, S., \& Mufti, Y. (2014). Pengembangan media pembelajaran IPA-fisika smartphone berbasis android sebagai penguat karakter sains siswa. Jurnal Kaunia, Vol. 10(1), pp. 59-64.

Kuswanto, J., \& Radiansah, F. (2018). Media Pembelajaran Berbasis Android Pada Mata Pelajaran Sistem Operasi Jaringan Kelas XI. Jurnal Media Infotama, Vol. 14(1).

Muyaroah, S., \& Fajartia, M. (2017). Pengembangan Media Pembelajaran Berbasis Android dengan menggunakan Aplikasi Adobe Flash CS 6 pada Mata Pelajaran Biologi. Innovative Journal of Curriculum and Educational Technology, Vol. 6(2), pp. 22-26. 
Novianti, A. \& Shodikin, A. Pengembangan Bahan Ajar Kalkulus Diferensial Berbasis Animasi Dengan Pendekatan Kontekstual dan Kearifan Lokal. De Fermat: Jurnal Pendidikan Matematika Vol. 1 (2), pp. $12-18$

Pramono, A. S. \& Sudarmilah, E. (2019). Rancang Bangun Game Edukasi "Petualangan Geometri" Berbasis Android. Jurnal Ilmiah SINUS, Vol. 17(2), pp. 23-38.

Purbasari, R. J., Kahfi, M. S., \& Yunus, M. (2013). Pengembangan aplikasi android sebagai media pembelajaran matematika pada materi dimensi tiga untuk siswa SMA kelas X. Jurnal Online Universitas Negeri Malang, Vol. 1(4), pp. 1-10.

Puteh, S. N., \& Salam, K. A. A. (2011). Tahap kesediaan penggunaan ICT dalam pengajaran dan kesannya terhadap hasil kerja dan tingkah laku murid prasekolah. Jurnal Pendidikan Malaysia, Vol. 36(1), pp. 25-34.

Rahmawati \& Shendri. (2016). Seminar Hasil TIMMS 2015. Diakses pada 15 Juli 2019 dari http://puspendik.kemdikbud.go.id/se minar/upload/Rahmawati-SeminarHasil-TIMSS2015.pdf.

Shodikin, A. 2017. Pengembangan Bahan Ajar Kalkulus Integral Berbasis Animasi. Aksioma: Jurnal Program Studi Pendidikan Matematika. Vol. 6(1), pp. 1-11.

Suryadi, A. (2007). Pemanfaatan ICT dalam pembelajaran. Jurnal Pendidikan Terbuka dan Jarak Jauh, Vol. 8(2), pp. 83-98.

Trianto. (2012). Mendesain Model Pembelajaran Inovatif-Progresif. Jakarta: Kencana Prenada Media Group. 